\title{
Real-Time Vibration Control of Rotor-Bearing System Based on Artificial Neural Networks and Active Support Stiffness
}

\author{
Mauwafak Ali Tawfik \\ Mechanical Engineering Department, University of Technology, Baghdad, Iraq \\ E-mail: 20040@uotechnology.edu.iq
}

\begin{abstract}
A real-time dynamic response of the rotor-bearing system is controlled through an active support stiffness designed and constructed for this purpose. It consists mainly of a variable, flexible beam length. A stepper motor with a screw is implemented to manipulate the beam length to the required optimum position. Hence, it works as active spring stiffness, which minimizes the vibration response for the system. Stiff support is fixed at a specified position on the beam, and it is provided with a small ball bearing at the point of contact with the rotor at the other end. An artificial neural network has been used to control the dynamic system response. Response simulation with real-time LabVIEW is conducted to play a role as an interface to deal with the required sensors' records and the rotation of the stepper motor. The results show that the controlled system is efficient in obtaining the optimum support stiffness for different rotational speeds of the driven motor, which gives, in turn, the optimum system dynamic response.
\end{abstract}

Keywords - active spring stiffness; artificial neural; rotor-bearing; LabVIEW; arduino controller.

\section{INTRODUCTION}

Rotating machinery has widely been used in industrial applications, including lathe machines, motors, steam and gas turbines, and compressors. The performance of such systems is entirely affected by vibration problems. As a result of the vibration response of the rotor-bearing system has paid the attention of the researchers. Different trails have been adopted to control the rotating machinery's dynamic response to the safe bandwidth of vibrations. Among those trails, the rotor-bearing system's active vibration control was studied using hybrid journal bearings to stabilize the amplitude of vibration by controlling the spring and damper characteristics using an oil pump. The oil pressure is stabilized [1]. Ricardo et al. [2] dealt with a rotor's active vibration control by using two stacks of piezoelectric ceramic orthogonally arranged in a plane at one of the bearings as control actuators. Also, the rotor ball bearing system's active vibration control was implemented by Andre et al. [3] through the automatic motion of one of the two ball bearings, affecting the rotor length between them and hence affecting the response of the system. Peter et al. [4] investigated the controlled kinematic excitation of the bearing shells to suppress the rotor-bearing system's vibration caused by the unbalance forces through computer simulation and experimental work. Cabera et al. [5] used a journal bearing based on two magneto-Rheological dampers to compensate for the unbalanced response of the rotorbearing system and PID speed controller for the rotor speed regulation. Jader et al. [6] studied the application of using materials made from special alloys (smart material) as actuators in the dynamic system to control its vibration response. Salazar et al. [7] dealt with a feedback-controlled lubrication regime based on the performance derivative controller implementing lubricated tilting-pad journal bearing. Abdur et al. [8] presented a paper that evaluates the use of an adaptive neuro-fuzzy inference system controller to suppress the vibration in a rotor-bearing system and compares it with the linear-quadratic regular controller method. Rajasthan et al. [9] introduced a work that focuses on controlling speed rotor systems by using electrorheological fluid as an external electric field yielding to alter the fluid viscosity the stiffness and damper coefficients. This is described as a semi-active vibration control system. Shaolin et al. [10] studied the robust control method of an active magnetic bearing-rotor, while the system passed the critical speed. The simulation and the experimental results show that the designed $\mu$-synthesis controller was efficient in suppressing the rotor vibration. Also, a study presented by Behnam et al. [11] concerning the implementation of a dynamic absorber system force brings the rotor system out of resonance and creating two new natural frequencies through the reconstruction of magnetic absorber controller software. Mohammed et al. [12] applied smart electrorheological-ER- elastomers support to the rotor dynamics to reduce the rotor system's vibration level. The simulation results revealed that ER's implementation in conventional bearing supports led to shift the critical speeds and reduced 
the amplitude of vibration. Yangho et al. [13] dealt with the periodic vibration problem caused by an unbalanced force existing in active magnetic bearing as the rotor spins. Shaolin et al. [14] proposed a phase compensation method to improve a flexible rotor's damping level close to the first bending critical speed. Antony et al. [15] studied the critical speeds of a rotating shaft fitted with eccentric balance sleeves. Its stiffness was catered for when considering passive control characteristics critical speeds of the system.

This paper introduces a method by which the rotorbearing system's vibration response is controlled via implementing an active elastic simply supported beam working as an active support spring. Figure 1 illustrates the overall system setup.

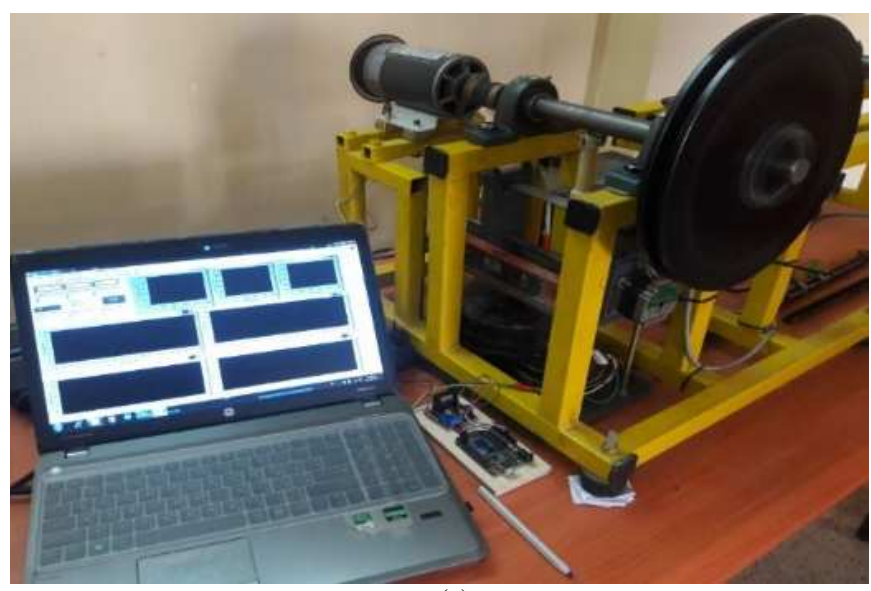

(a)

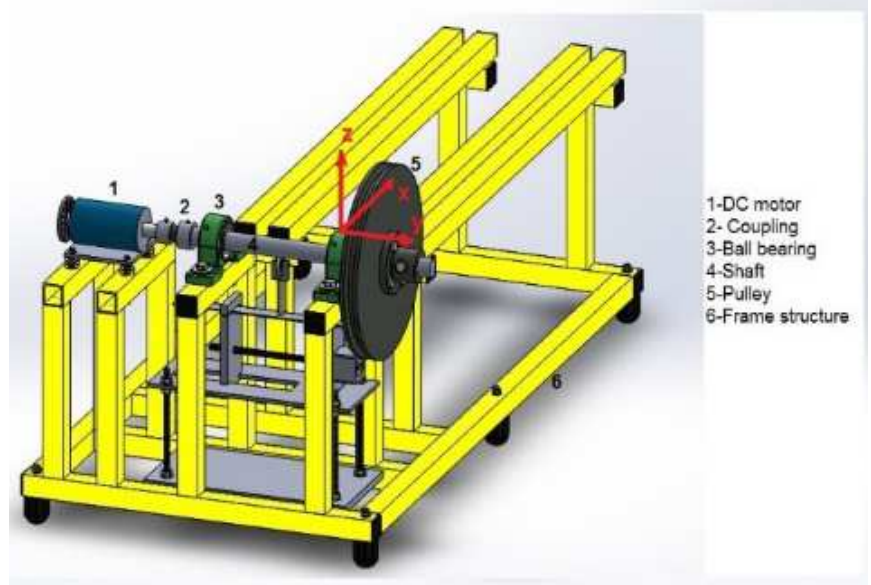

(b)

Fig. 1 (a) Experimental set up, (b) Main parts of the test rig

This work's motivation is taken from the fact of sacking a novel method of the vibration suppressing for rotating machinery through designing active elastic support and implementing it with a control system to improve the realtime dynamic response of the cited machinery.

The list below shows the summarized new contribution of this paper:

- The active elastic beam element device was designed and manufactured.

- The device was implemented with a vibrated system mainly composed of a rotor-bearing. It was efficient to suppress the vibration of the designated system for different values of rotating speeds.
- LabVIEW program is designed and constructed to help the control system choose the optimum spring stiffness value by implementing the elastic beam device.

- Applicable control system based on artificial neural networks was developed and trained, and it was efficient to attenuate the vibration of the system to minimize the acceleration RMS of vibration.

In the following subsections, an introduction to the modeling of the active stiffness system is provided first. Then, the construction of the rotor-bearing and sensory system is described. The block diagram of the constructed LabVIEW code is discussed. After that, control modeling based on artificial networks with its architecture and training is illustrated. The obtained results are then thoroughly discussed. Finally, the main points of the paper's conclusions are provided.

\section{MATERIAL AND METHOD}

\section{A. Modeling of the Active Stiffness System}

Consider the system shown in Figure 2. The elastic beam is considered an active spring; its stiffness value is changeable with the beam length's alternation. The support is fixed in its position where the dynamic load is acting upon it and in turn to the elastic beam. The beam is considered a simply supported beam resting on a knife-edge at each support, as shown in the referred figure. The left support allows the elastic beam to slide through it while the right support is fixed. From the strength of the material, the deflection of the beam freely supported at the ends with a concentrated load at a specified point is given by Timoshenko, [16] as follows:

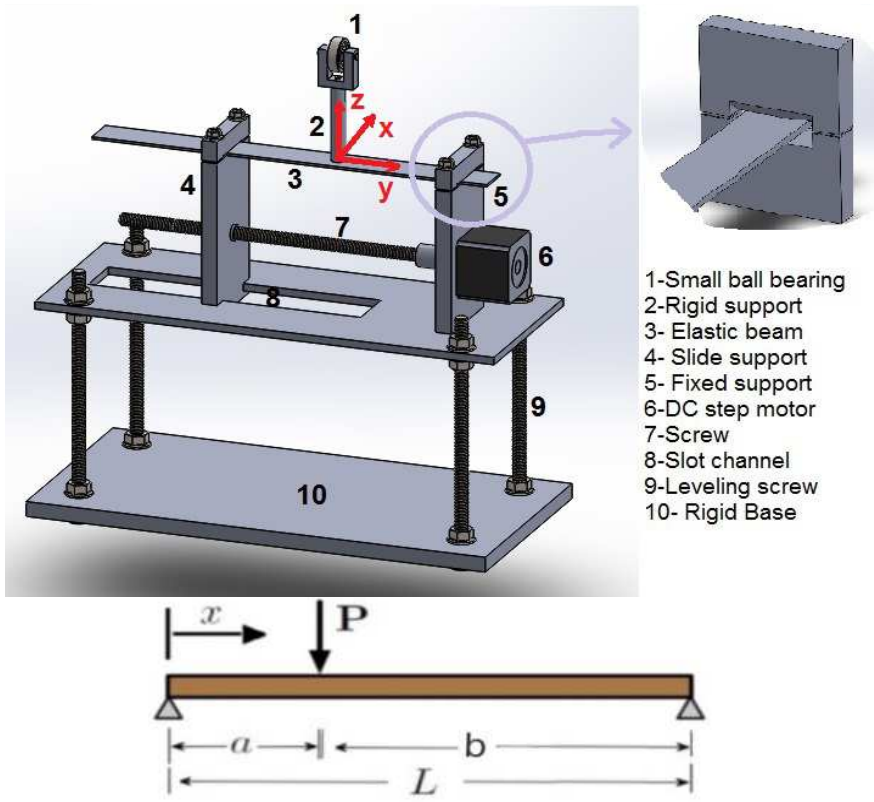

Fig. 2 Active stiffness system

$$
\begin{aligned}
& \mathrm{Y}=\frac{P b x}{6 E I L}(\mathrm{~L} 2-\mathrm{x} 2-\mathrm{b} 2) \\
& \frac{P}{Y}=K=\frac{6 E I L}{b x\left(L^{2}-x^{2}-b^{2}\right)}
\end{aligned}
$$


Where $\mathrm{K}$ is the stiffness of the elastic beam.

When $\mathrm{x}=\mathrm{a}$, i.e., the deflection at the concentrated load, then:

$$
\mathrm{K}=\frac{6 E I L}{b a\left(L^{2}-a^{2}-b^{2}\right)}
$$

Hence, for any changeable distance (a), there is a specific value for the elastic beam stiffness coefficient.

\section{B. Rotor-Bearing and Sensory System Description}

The system is composed of a rotor mounted on two identical ball bearings, which rested in a steel structure, as shown in Figure 1. A pulley is mounted on the right end of the rotor overhang. In contrast, the left end is connected to a rubber coupling through a DC drive motor (permanent magnet DC motor model ZY82SL-2, Fezeoc Lemmar Elctrical Technology Co. LTD). The DC motor has a variable speed rating up to 3800 r.p.m. A thin small accelerometer of 3-axis (ADXL335) is mounted on the right ball bearing cup. Arduino Mega 2650 board was implemented to control the signal from the accelerometer to the laptop computer.

The active stiffness system is provided by drive stepping motor (step - sgn, Sanyodenki No.10602, Type JD3H67011141 , made in japan) rotates the screw bar by any required turns within the specified range. This is done by moving the sliding support to any required position. Another Arduino board (UNO R3) was used to control the running of the stepped motor via the laptop computer.

\section{Block Diagram and LabVIEW Description}

The records of the accelerometer are transmitted via the LabVIEW program. The LabVIEW is software that can be used by the user relying on icons to construct different applications through a graphical programming language. The LabVIEW contains a user interface (front panel) that can be constructed via the implementation of a set of tools and objects. Another panel controls the front panel objects, referred to as the block diagram. LabVIEW programs are considered virtual instruments to fulfill the physical instrument functions such as oscilloscope and other time meters. Figure 3 and Figure 4 illustrate the developed data acquisition software for vibration records signal in $\mathrm{X}, \mathrm{Y}$ and $\mathrm{Z}$ and the software for stepped motor function. Vibration signals in time and frequency domains captured from the system were cured by (FFT) in X, Y and Z directions.

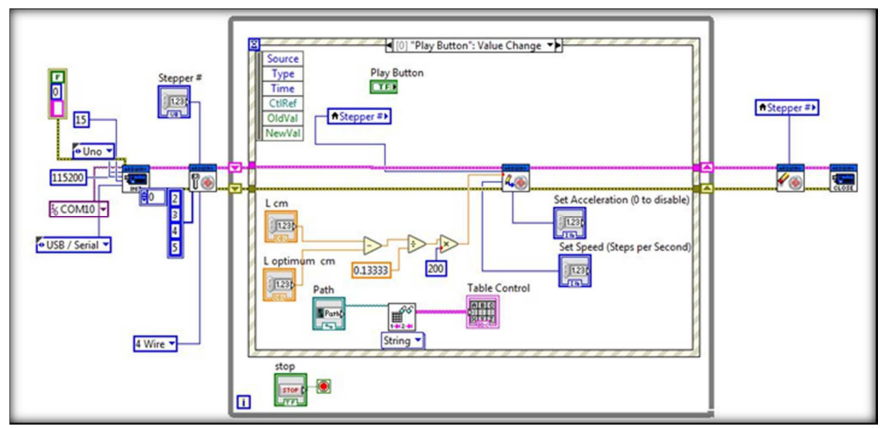

Fig. 3 Block diagram software for stepped motor function based on Arduino and LabView

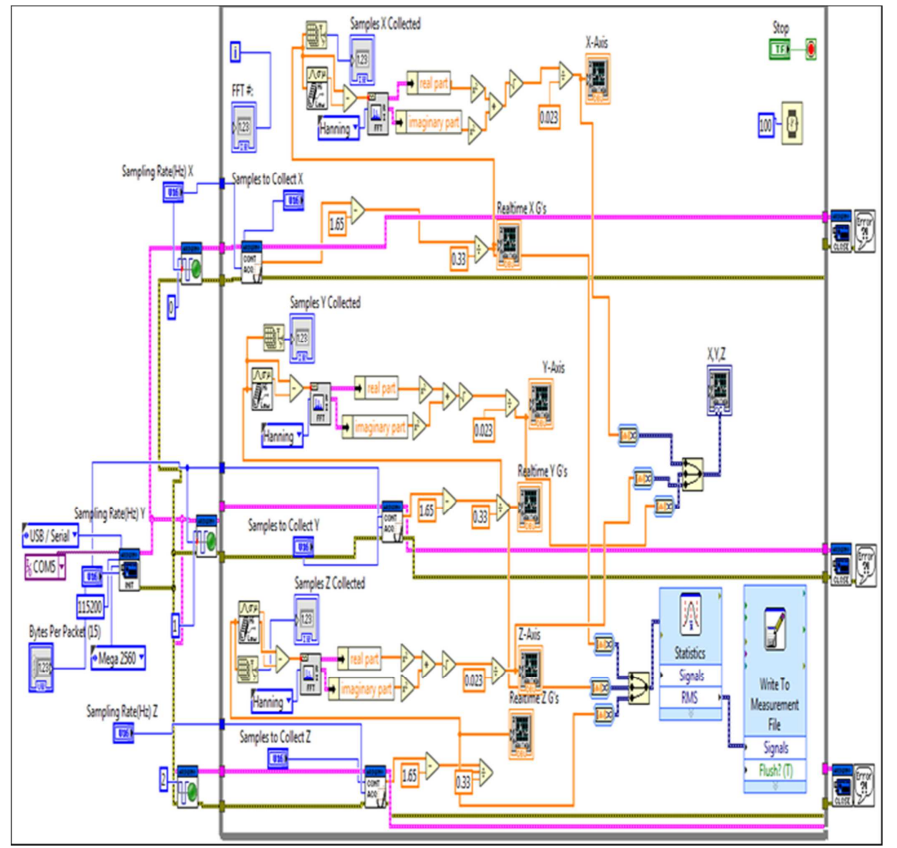

Fig. 4 Designed data acquisition software for vibration signal in (x, y, and z) based on Arduino and LabVIEW

\section{Controlling Modeling Based on Artificial Neural Network (ANN)}

The artificial neural network is implemented and trained to control the vibration data obtained from the LabVIEW. These data contain the average RMS of system vibration signal at different elastic beam lengths, hence different support spring stiffness and different drive motor speed values. The artificial Neural Network is trained to imply an optimum beam length to give the lowest RMS of system vibration via active spring stiffness at each conducted motor speed. The artificial network output is stored in Excel file from which it is conducted to the Arduino panel and, in turn, to the LabVIEW program. The LabVIEW program gives an order to the stepping motor to rotate the screw to the required position to give minimum RMS of the vibration signal according to the following equation:

$$
\text { No. of screw turns }=\frac{l_{\text {optimum }} l_{O}}{\text { screw pitch distance per each turn }}
$$

Where:

$l_{\text {optimum }}$ : The optimum distance from the sliding support to the active spring point of contact with the rotor gives minimum RMS.

$l_{o}$ : The instantaneous distance between the sliding support and the active spring point of contact for the case when minimum RMS is required $\left(l_{o}=a\right)$.

If the number of turns is negative, the stepped motor shaft will rotate in a counter-clockwise and vice versa when the number of turns is positive.

\section{E. Artificial Neural Network Architecture}

The feed-forward neural network is applied. It has a single hidden layer with 10-neurons of tan-sigmoid transfer function. The input layer has four neurons representing average RMS in $\mathrm{x}, \mathrm{y}$, and $\mathrm{z}$ for the system. This study also involved the angle of RMS vector (theta) with the ( $x$ y) plane, motor speed and the distance from the sliding support 
to the point of contact of the support with the rotor $\left(l_{0}\right)$. The output layer has only one neuron representing the optimum distance $\left(l_{0}\right)$, which gives minimum resultant RMS of vibration for the vibrating system when the elastic spring in contact with the rotor. Each neuron receives its input directly from the previous layer and sends its output directly to the neuron in the next layer, as shown in Figure 5. Figure 6 illustrates the overall control system.

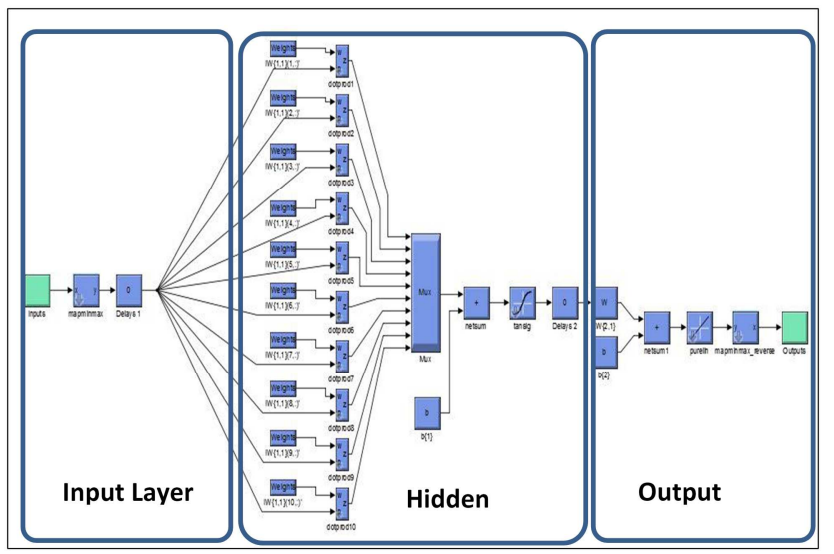

Fig. 5 The architecture of the artificial neural networks

\section{F. Artificial Neural Network Training and Testing}

The Levenberg-Marquardt backpropagation training algorithm is implemented as a technique for this regard because it is such an efficient and fast algorithm [17]. Matlab R2014a has been used to conduct the training and test procedures. Number of RMS records data were 1800 for each record of $\mathrm{x}, \mathrm{y}$, and $\mathrm{z}$ at different beam lengths and range of drive motor speeds $(400,500,600,800,1000$, and 1300) r.p.m. The average value of RMS in each direction was taken for different speed and beam length values. The RMS components in the cited directions for each RMS and its inclination (theta) were calculated and implemented as samples for training with the designated speeds and beam lengths.

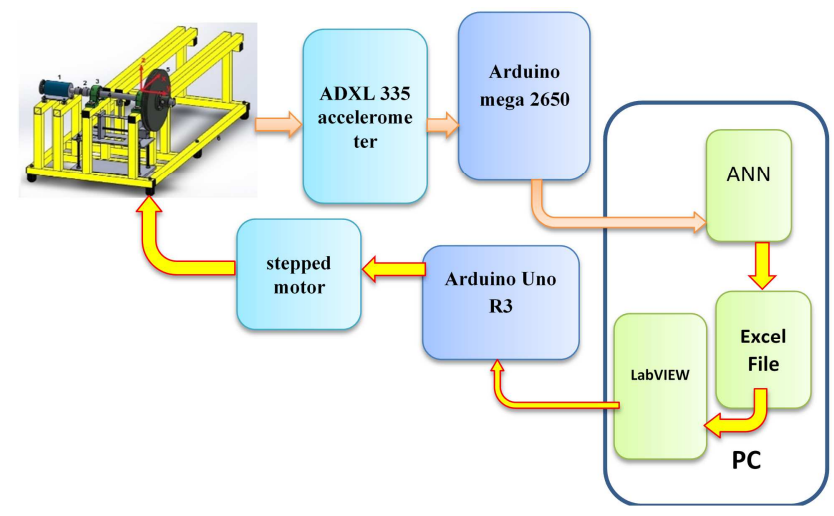

Fig. 6 Block diagram of system control connections

\section{RESULT AND DISCUSSION}

Figures 7 and 8 illustrate the validation performance of ANN and the histogram simultaneously. These figures show that the training iteration number is 23 , and the best validation performance is $2.67 \times 10^{-23}$. Errors between the target and the output range from $5.68 \times 10^{-13}$ to $2.3 \times 10^{-11}$, which gives a good indication for efficient training. Table 1 shows the acceleration RMS of vibration for the system in $\mathrm{x}$, $\mathrm{y}$, and $\mathrm{z}$ directions with their resultant and its inclined angles. Also, it shows the distance of the sliding support to the position of contact with the rotor (lo) with the optimum distance, which gives minimum RMS of vibration. Figure 9 and Figure 10 show the resultant of acceleration RMS of vibration versus (lo) for different values of rotor speeds in $3 \mathrm{D}$ and $2 \mathrm{D}$. It can be seen from these figures that the minimum value of RMS, for an instant, at 1300 r.p.m. the minimum RMS (1.853) occurs at $l o=10 \mathrm{~cm}$. In Table 1 , the control system shows that at any other position of lo the stepped motor will rotate the screw to stop at loptimum of $10 \mathrm{~cm}$ to give the minimum resultant of RMS. Also, at rotor speeds of 1000 r.p.m., RMS's minimum value is 1.843 at $10=20 \mathrm{~cm}$. Then again, from Table 1 , it shows that the control system will order the stepped motor to rotate the screw to stop at loptimum of $20 \mathrm{~cm}$ for any other position to give the minimum resultant of RMS of vibrations and so on for other values of rotor speeds. This indicates that the control system is efficient by which it chooses the optimum position to give the stiffness coefficient of the elastic beam (see Eq. (3)), and the minimum RMS of vibration is maintained through the screw rotation by the stepped motor at this position.

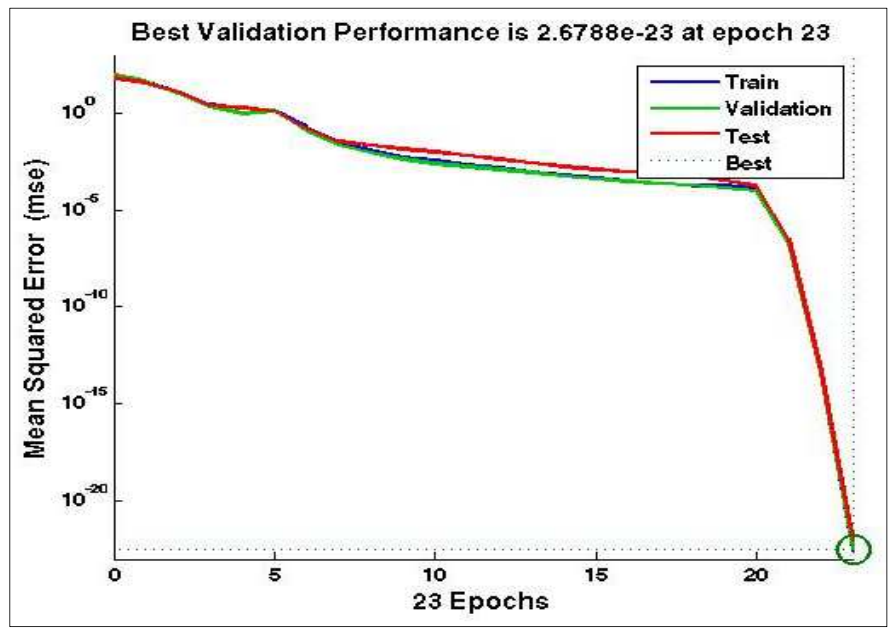

Fig. 7 Validation performance of the artificial neural networks

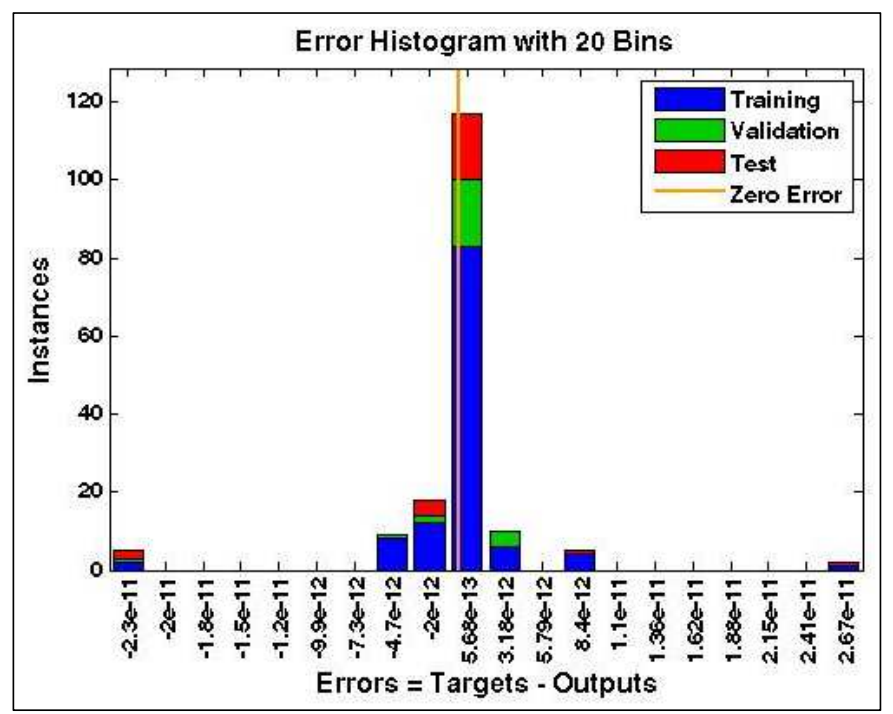

Fig. 8 Histogram of the artificial neural networks 
TABLE I

ACCELERATION RMS OF VibRATION FOR THE SYSTEM IN (X, Y, AND Z) DiRECTION WITH THEIR RESULTANT AND ITS INCLINED ANGLES WITH (X-Y) PLANE

\begin{tabular}{|c|c|c|c|c|c|c|c|}
\hline $\begin{array}{l}\boldsymbol{R P} \\
M\end{array}$ & $\begin{array}{l}\text { RMS (X) average } \\
\mathrm{m} / \mathrm{s}^{2}\end{array}$ & $\begin{array}{l}R M S(Y) \\
\text { average } \mathrm{m} / \mathrm{s}^{2}\end{array}$ & $R M S(Z)$ average $\quad \mathrm{m} / \mathrm{s}^{2}$ & $\begin{array}{l}R M S \\
\text { resultant } \\
\mathrm{m} / \mathrm{s}^{2}\end{array}$ & $\begin{array}{l}\text { Theta } \\
\text { (rad) }\end{array}$ & $L_{o}(\mathrm{~cm}$ & $\begin{array}{l}\text { L(cm) } \\
\text { optimum }\end{array}$ \\
\hline 1300 & 1.3126977 & 1.3083117 & 1.313083181 & 1.85360923 & 0.7872183 & 10 & 10 \\
\hline 1300 & 1.3377292 & 1.3322048 & 1.337539655 & 1.88779824 & 0.7873964 & 12 & 10 \\
\hline 1300 & 1.3256946 & 1.3175740 & 1.324786537 & 1.86843803 & 0.7881277 & 14 & 10 \\
\hline 1300 & 1.3618178 & 1.3540822 & 1.36146022 & 1.92018558 & 0.7881151 & 18 & 10 \\
\hline 1300 & 1.3255706 & 1.3180001 & 1.325385976 & 1.86916355 & 0.7881922 & 20 & 10 \\
\hline 1000 & 1.4032558 & 1.3982611 & 1.40321614 & 1.98094671 & 0.7871669 & 10 & 20 \\
\hline 1000 & 1.4425537 & 1.4386235 & 1.442525089 & 2.0372816 & 0.7867523 & 12 & 20 \\
\hline 1000 & 1.3981194 & 1.3929698 & 1.397693071 & 1.97329949 & 0.7870907 & 14 & 20 \\
\hline 1000 & 1.3441220 & 1.3390181 & 1.3442254 & 1.89734328 & 0.7873388 & 18 & 20 \\
\hline 1000 & 1.3062506 & 1.3013544 & 1.306029186 & 1.84370159 & 0.7871911 & 20 & 20 \\
\hline 800 & 1.3393084 & 1.3325290 & 1.339025 & 1.88907959 & 0.7878297 & 10 & 16 \\
\hline 800 & 1.3358302 & 1.3300428 & 1.336675722 & 1.88566062 & 0.7878854 & 12 & 16 \\
\hline 800 & 1.3377845 & 1.3332723 & 1.33754478 & 1.88855528 & 0.7869979 & 14 & 16 \\
\hline 800 & 1.3315137 & 1.3271523 & 1.332033489 & 1.8803315 & 0.7872337 & 16 & 16 \\
\hline 800 & 1.3656055 & 1.3604708 & 1.365790795 & 1.92776176 & 0.7873495 & 18 & 16 \\
\hline 600 & 1.3358718 & 1.3303783 & 1.33581593 & 1.88528794 & 0.7874376 & 10 & 10 \\
\hline 600 & 1.3402930 & 1.3339628 & 1.339890214 & 1.89070428 & 0.7876149 & 12 & 10 \\
\hline 600 & 1.340058 & 1.3339537 & 1.339832 & 1.89065659 & 0.7875966 & 14 & 10 \\
\hline 600 & 1.3408833 & 1.3351664 & 1.340743238 & 1.89215801 & 0.7874822 & 16 & 10 \\
\hline 600 & 1.3419331 & 1.3347445 & 1.341791844 & 1.8926036 & 0.7880311 & 18 & 10 \\
\hline 600 & 1.3453364 & 1.3390728 & 1.3451786 & 1.89805731 & 0.7876728 & 20 & 10 \\
\hline 500 & 1.3119457 & 1.3117989 & 1.306053016 & 1.85110535 & 0.7832033 & 10 & 15 \\
\hline 500 & 1.3138344 & 1.3099485 & 1.313775248 & 1.85525484 & 0.7868567 & 12 & 15 \\
\hline 500 & 1.3023845 & 1.2970407 & 1.302399806 & 1.83808597 & 0.7874598 & 15 & 15 \\
\hline 500 & 1.3035972 & 1.3010137 & 1.303503737 & 1.8416728 & 0.7863542 & 17.5 & 15 \\
\hline 400 & 1.3232908 & 1.3104152 & 1.32356702 & 1.86252992 & 0.7903913 & 10 & 16 \\
\hline 400 & 1.3200478 & 1.3063979 & 1.319990167 & 1.85716174 & 0.7905734 & 12 & 16 \\
\hline 400 & 1.3221370 & 1.3127089 & 1.322040049 & 1.86306057 & 0.7889397 & 14 & 16 \\
\hline 400 & 1.3188004 & 1.3056412 & 1.318974643 & 1.85590762 & 0.7904783 & 16 & 16 \\
\hline 400 & 1.3469885 & 1.3335689 & 1.346962214 & 1.89544539 & 0.7903946 & 20 & 16 \\
\hline
\end{tabular}




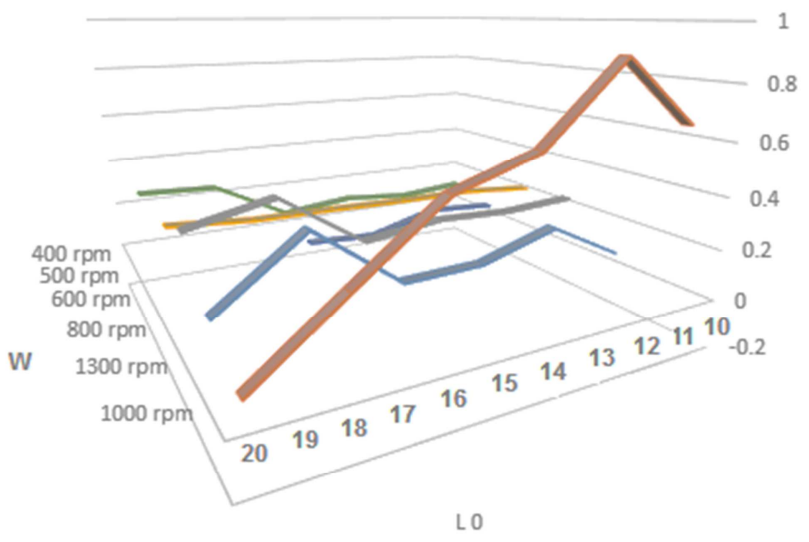

$\square 1000 \mathrm{rpm} \quad \square 1300 \mathrm{rpm} \quad \square 800 \mathrm{rpm} \quad \square 600 \mathrm{rpm} \quad \square 500 \mathrm{rpm} \quad \square 400 \mathrm{rpm}$

Fig. 9 3D chart for different values of R.p.m, Lo(cm) and acc.R.M.S. of vibration in decibel.
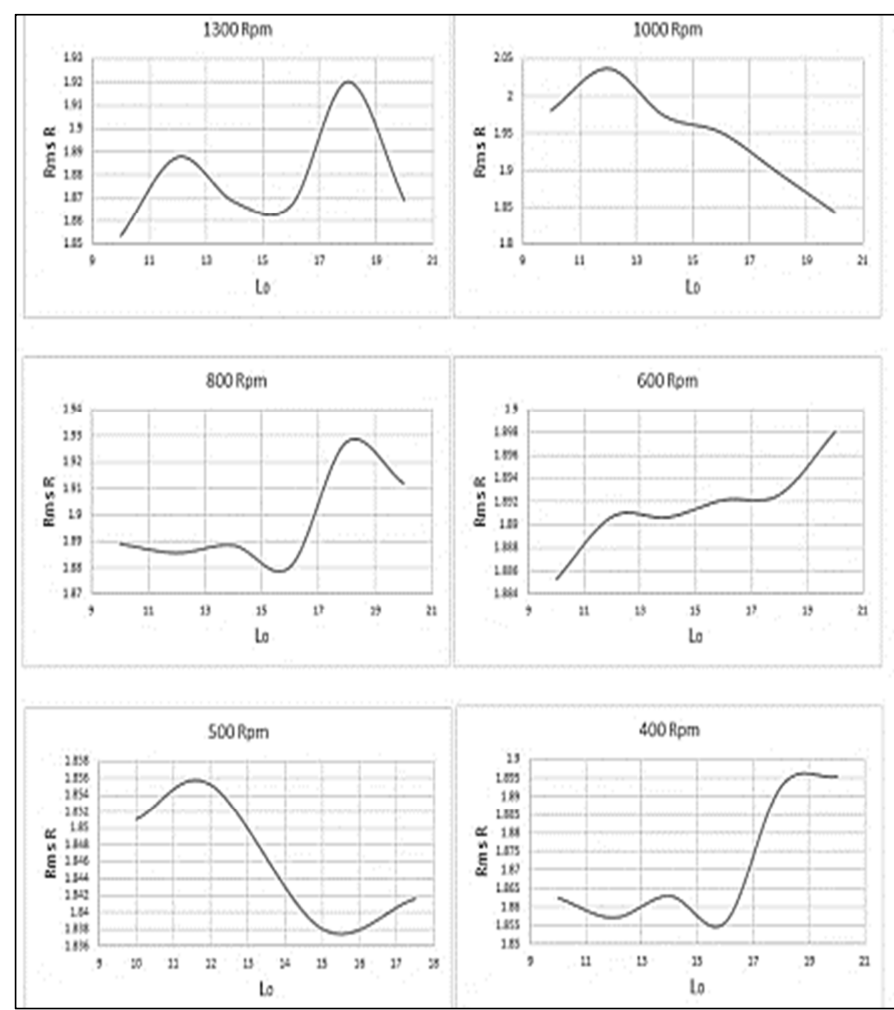

Fig. 10 Resultant of acceleration RMS of vibration versus Lo for different values of motor speed.

\section{CONCLUSION}

A device of active stiffness was designed and manufactured; this device was implemented with a test rig of a rotor-bearing system to attenuate its vibration to RMS's minimum value for the used data via choosing an optimum sliding position by which it gives an optimum spring stiffness value for this regard. A control system was designed using the LabVIEW program and artificial neural networks, which shows a good convergence to the experimental results. The control system was efficient in attenuating the vibration of the rotor-bearing system to the minimum values at each running speed of the drive motor.

\section{REFERENCES}

[1] Blanco - Ortega,A., Silva - Navarro,G., and Gomez - Mancill ,j.c., Active Vibration Control on a Rotor Bearing System Using Hybrid Journal Bearings, Twelfth international congress on sound and vibration, Lisbon, 11(1), July 2005.

[2] Ricardo C. Simoes, Valder Steffen, Jr.,Johan Der Hagopain, and Jarir Mahfoud, Model Active Vibration Control of a Rotor Using Piezoelectric Stack Actuators, Journal of Vibration and Control,13(1), pp.45-6, January 2007.

[3] Andre's Blanco - Ortega, Francisco Beltran Carbajal, Gerardo Silva Navaro, and Marco Antonio Oliver Salazar, Active Vibration Control on a Rotor Bearing System Based on Dynamic Stiffness, Rev, Fac, Ing. Univ, Antioquia, 55 pp. 125-133, Sep.2010.

[4] Peter Ferefcki, Roman Sikora, and Zdenek Poruba, Numerical Simulation of Feedback Controlled Fluid - Induced Instabilities in Rotor System Supported by Hydro - Dynamic Bearings, Archives of Control Sciences, 20 (LVI) (3), pp. 287-301,2010.

[5] Cabrera - Amado,A., and Silva - Navaro, G., Semi Active Vibration Absorption in a Rotor - Bearing System Using a PPF Control Sheme, proceeding of ISMA 2012 - USD, pp. 205-222, January 2012.

[6] Jader M. Borges, Antonio Silva, A., Carlos J. de Aroujo, Eisenhawer de M. Fernandes, Roberto Leal Pimental,and Alberdan A. Santigo, Rotor - Bearing Vibration Control System Based on Fuzzy Controller and Smart actuators, int. Jnl of Multi Physics, 7(3), pp. 197-206, September 2013.

[7] Salazar, J.G., and Santos, Feedback Controlled Lubrication for Reducing the Lateral Vibration of Flexible Rotors Supported by Tilting - Pad Journal Bearings, Proceeding of the Institution of Mechanical Engineering Part J, Journal of Engineering Technology, 208 - 210(10), pp. 1994-1998, April 2015.

[8] Abdur Rosyid, Mohannad Alata, and Mohammed Elmadany, Adaptive Neuro - Fuzzy Inference System Controller for Vibration Control of Reduced - Order Finite Elements Model of Rotor Bearing - Support System, International Letters Chemistry, Physics and Anstromy, ISSN 2299-3843, 55(1), PP. 1-11., July 2015.

[9] Rajasethara Reddy Mutra, and srinivas, J., Semi-Active Vibration Control of High-Speed Rotor System with Electro - Rheological Bearing, MATEL web conferences, 211, 14008, October 2018.

[10] Shaolin Ran, Yefa Hu, Hauchun Wu, and Xin Cheng, Resonance Vibration Control for AMB Flexible Rotor System Based on $\mu$ Synthesis controller, Mathematical Problems in Engineering's, 2018, Article ID 4362101, 16 pages, Dec. 2018.

[11] Behnam Monjezi and and Hamidreza Heidari, Active Vibration Control of Rotor - Bearing System by Virtual Dynamic Absorber, Eur. Phys. J. Appl. Phys.,86(3), pp. 10, June 2019.

[12] Mohammed Alhussein, Hamid Moeeufard, and Jalil Razaee Pazhand, Vibration Attenution of Rotor - Bearing Systems Using Smart Electro- Rheological Elastomer Supports, Journal of the Barazilian Socity of Mechanical Sciences and Engineering,41(6), June 2019.

[13] Yangho Zheng, Nimo. Yan Zhou, and Zhengang Shi, Unbalance Compensation and Automatic Balance of Active Magnetic Bearing Rotor System by Using Iterative Learning Control, IEEE Access, 7, pp. 122613 - 122625, August 2019.

[14] Shaolin Ran, Yefa Hu,Huachun Wu, and Xin Cheng, Active Vibration Control of Flexible High Speed Rotor with Magnetic Bearings Via Phase Compensation to pass Critical Speed, Journal of Low Frequency Noise, Vibration and Active Control, 9(17), Dec. 2019.

[15] Antony Kirk, and Jonothan Griffiths, On the Importance of Sleeve Flexibility in Pasive Control of Critical Speeds of a Rotatng Shaft Using Eccentric Sleeves, Journal Machines, 7(3), Sep. 2019.

[16] Timoshenko, S., Elements of Strength of Materials, Divan Nostrand company, INC, England, 1968. (Book).

[17] Hegan, M. T., and Menhaj, M.B, 1994, Training Feed Forward Networks with the Marquardt Algorithm, IEEE Transaction on Neural Networks, 5(6), November. 1994. 